\title{
PREPARATION AND CHARACTERIZATION OF ALUMINA AND SILICA MODIFIED CHITOSAN
}

\author{
P. Saraswathi ${ }^{1}$ and M. Makeswari ${ }^{2}$,* \\ ${ }^{1}$ Department of Chemistry, JCT College of Engineering and Technology, \\ Coimbatore-641105, Tamil Nadu, India. \\ ${ }^{2}$ Department of Chemistry, Karpagam Academy of Higher Education, Karpagam University, \\ Coimbatore-641021, Tamil Nadu, India. \\ *E-mail: makeshvu3@gmail.com
}

\begin{abstract}
In this present work, the modified chitosan composite is prepared by using Alumina and Silica. The prepared composites are characterized by SEM, EDAX, XRD and FTIR techniques. The physiochemical characteristics such as Carbon Yield (\%), Moisture content, $\mathrm{pH}$, Acidity and Basicity, Zero point charge, Boehm's titration, Iodine number are also carried out. The yield and iodine number of chitosan modified silica $91.6 \%$ and $2743.555 \mathrm{mg} / \mathrm{g}$ is higher than the chitosan modified alumina $85.2 \%$ and $2121.457 \mathrm{mg} / \mathrm{g}$. The prepared composites are used as remarkable adsorbents in the treatment of wastewater due to its biodegradable and non-toxic nature.
\end{abstract}

Keywords: chitosan, Characterization, alumina, silica, modification, wastewater.

@ RASĀYAN. All rights reserved

\section{INTRODUCTION}

The color is an important aspect of human life. Coloring process in industries is done using dyes. A dye is a colored substance that has an affinity to the substrate to which it is being applied. Today commercially more than 10,000 dyes are available. ${ }^{1}$ Dyes are mostly used in industries like textiles, paper, printing, leather and plastics. ${ }^{2}$ Common pollutants in textile effluents are dyes which are toxic, non-degradable due to their complex structure. As a result, the toxic effluents pose a huge risk to the environment if discharged untreated. ${ }^{3}$ Due to increase in population and developmental work wastewater recovery, recycling and reuse are necessary to meet the water requirements for domestic uses, irrigation and industry. ${ }^{4}$ Wastewater can be recovered from various sources such as agricultural return flows, industrial wastewater, stormwater and municipal wastewater. Water can be reclaimed by various methods on the basis of the presence of physical, chemical and biological constituents. ${ }^{5}$ Extensively reported methods for color removal are coagulation, ultra-filtration, chemical oxidation, electrochemical, adsorption and photo oxidation. ${ }^{6}$

Activated carbon is a material which is used for the removal of dyes due to the high capacity of adsorption of various kinds of dyes, but its use is limited because of the high cost. A large variety of lowcost materials as an alternative of activated carbon have been investigated for their ability to remove dyes. ${ }^{7-9}$ Chitosan a cationic polymer from natural resources has received much interest of the researchers, due to its inexpensive, biodegradability, non-toxic and environment-friendly. ${ }^{10}$ Chitosan is a straight chain copolymer is made of (1-4)-linked D-Glucosamine and N-Acetyl - D-Glucosamine. Deacetylation of Chitin yields chitosan. Chitosan is the second abundant polymer in nature after cellulose. ${ }^{11}$ The number of amino groups present in the chitosan can uptake more pollutants than chitin, which has few percentage of amino groups. ${ }^{12-14}$ The hydroxyl groups and amino groups of the chitosan can be chemically modified. ${ }^{15-17}$ Chemical modification of chitosan enhances the uptake capacity of the pollutants. ${ }^{18,19}$ It is used in a number of fields including agriculture, medicine, textile, wastewater treatment. The present work focuses on the preparation and characterization of Chitosan modified with Alumina and Silica. 


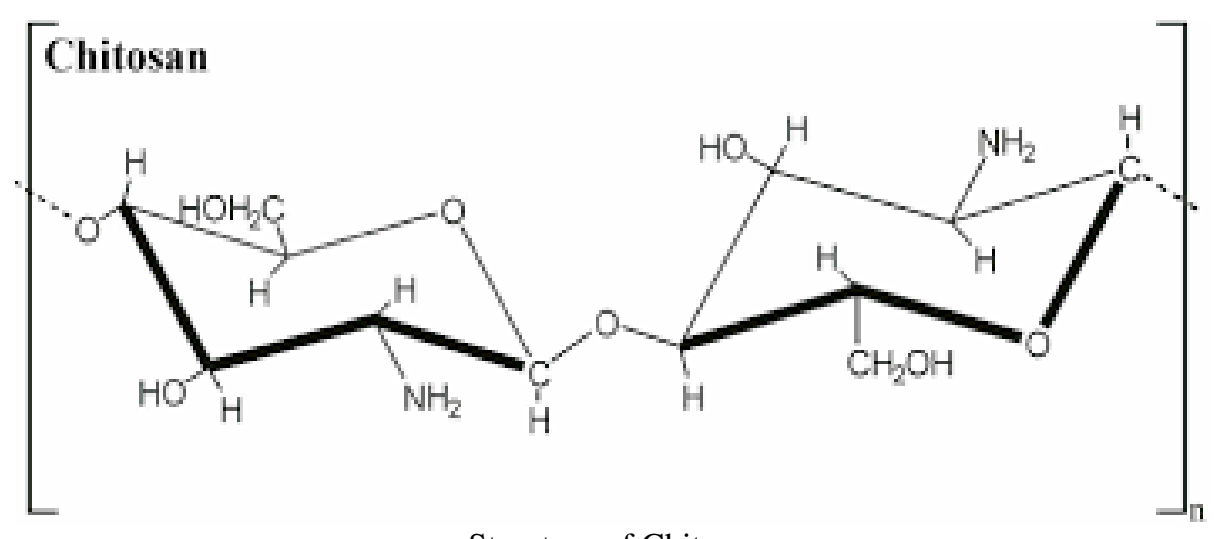

Structure of Chitosan

\section{Materials and Methods}

\section{EXPERIMENTAL}

Chitosan Alumina Composite (CAC) and Chitosan Silica Composite (CSC) are prepared by using chitosan as a biotemplate; A. R. grade acetic acid, ammonia solution, A. R. grade aluminum nitrate, silica gel, sodium hydroxide, and ethanol are procured from Universal Scientific Company, India. Double distilled water is used in the entire synthesis.

\section{Preparation of Chitosan Alumina Composite (CAC)}

Chitosan Alumina Composite is prepared by dissolving chitosan in 5\% acetic acid. Aluminum nitrate solution is gradually added to the chitosan slurry and stirred in a laboratory for an hour at room temperature using magnetic stirrer. 1:3 is the molar ratio of chitosan and aluminum nitrate. The obtained aluminum chitosan solution is added to 50\% ammonium hydroxide solution under stirring. The resultant product formed is filtered from ammonium hydroxide solution and is dried at ambient temperature. Dried product is calcinated and powdered for further studies. ${ }^{20}$

\section{Preparation of Chitosan Silica Composite (CSC)}

To prepare Chitosan Silica Composite, chitosan is dissolved in $1 \mathrm{M}$ acetic acid and this mixture is kept in a magnetic stirrer for 2 hours and then silica is added to this mixture and the stirring is continued for another 1 hour to reach homogeneity. The resultant mixture is kept for 8 hours in a stable place to obtain a bubble-free mixture. The weight ratio of chitosan to silica is $2: 1$.To this mixture sodium hydroxide and ethanol is added. Then, it is stored in the solution for $24 \mathrm{~h}$ to allow the composite to be formed. The resultant product is separated from the solution and washed with deionized water several times to remove impurities. ${ }^{21,22}$ The obtained composite is dried at room temperature. Finally, dried form of the composite is crushed, powdered and stored in an airtight container for further studies.

\section{Characterization}

\section{Physiochemical characterization}

The characteristics of the composites such as Yield, Moisture content, $\mathrm{pH}$, Determination of surface acidity and basicity, Zpc and Iodine number is determined for the prepared Chitosan Alumina and Silica composites. The yield of the prepared composites is determined by using:

$$
\operatorname{Yield}(Y)=\left(M / M_{0}\right) \times 100 \text {. }
$$

The moisture content of the prepared composites is determined by using the following equation:

$$
\text { Moistue content }(\%)=[(M-X) / M] \times 100 \text {. }
$$

The composite is dissolved in the distilled water, boiled and the $\mathrm{pH}$ is measured by using digital $\mathrm{pH}$ meter. 
Surface acidity and basicity are determined by mixing $0.2 \mathrm{~g}$ of the composite with $25 \mathrm{ml}$ of $0.5 \mathrm{M} \mathrm{NaOH}$ and $0.5 \mathrm{M} \mathrm{HCl}$ in a closed flask and agitated for $10 \mathrm{hrs}$ at room temperature. After agitation, the mixture is filtered and the filtrate is titrated with $0.5 \mathrm{M} \mathrm{HCl}$ and $0.5 \mathrm{M} \mathrm{NaOH}$ using phenolphthalein as indicator.

\section{Zero Point Charge}

$0.2 \mathrm{~g}$ of the composite is added to a solution of sodium nitrate of concentration $0.01 \mathrm{M}$, whose $\mathrm{pH}$ is adjusted with $0.01 \mathrm{M} \mathrm{NaOH}$ and $0.01 \mathrm{M} \mathrm{HNO}_{3}$ and final $\mathrm{pH}$ is measured. The results are plotted with initial $\mathrm{pH}$ vs $\Delta \mathrm{pH}(\Delta \mathrm{pH}=$ final $\mathrm{pH}$ - initial $\mathrm{pH})$. The $\mathrm{pH}$ equals to zero, yielded $\mathrm{pH}_{\mathrm{zpc}}$ of the carbon. ${ }^{23}$

\section{Determination of the amount of Iodine adsorbed}

The composites are characterized by using Iodine number as a fundamental parameter. Iodine number is used to measure the micropore content of the composite and is obtained by adsorption of Iodine from a solution by the composite. The large surface area of the composite particles is due to the number of pores and is increased during the activation process. ${ }^{24}$

\section{Determination of surface group (Boehm's Titration)}

The composite is taken in the $50 \mathrm{ml}$ conical flask and $20 \mathrm{ml}$ of different bases are added in the volumetric standards. The flask is then sealed and agitated in a shaker for 3 days. Filter these solutions separately and $5 \mathrm{ml}$ of each filtrate is titrated with $0.1 \mathrm{M} \mathrm{HCl}$ using a water-ethanol solution of methyl orange as an indicator. The number of basic sites is calculated from the amount of $\mathrm{HCl}$ reacted with the composite. ${ }^{25}$

\section{Surface Characterization}

Fourier Transform Infrared Spectroscopic analysis is determined by Jasco-460 plus to get the structural information of chitosan composites. The scanning electron microscope and elemental spectra are used to find out the surface morphology of the modified composites by using JSM 6390 model. X-ray diffraction is carried out by using XRD 6000 model. Qualitative determination and elements localization of the composites are allowed during SEM observations.

\section{RESULTS AND DISCUSSION \\ Physiochemical Characterization of Chitosan Alumina Composite (CAC) and Chitosan Silica Composite (CSC)}

Characteristics of the adsorbents such as yield, iodine value, moisture content, $\mathrm{pH}$, surface acidity and basicity of Chitosan Alumina Composite and Chitosan Silica Composite are determined. The results are summarized in Table-1. The results show the moisture content of the CAC $(2.77 \%)$ is more than CSC $(0.52 \%)$. The high moisture content of the composite will dilute the action of the composite and it is necessary to utilize extra load of the composite..$^{26}$

Table-1: Physiochemical Characterization of CAC and CSC

\begin{tabular}{l|l|l}
\hline Parameters & CAC & CSC \\
\hline Yield \% & 85.2 & 91.6 \\
\hline Moisture content \% & 2.77 & 0.52 \\
\hline $\mathrm{pH}$ & 5.05 & 6.55 \\
\hline Surface acidity (mmoles/gm) & 3.25 & 3.775 \\
\hline Surface basicity (mmoles/gm) & 4.00 & 4.164 \\
\hline ZpC & 6.5 & 7.8 \\
\hline $\begin{array}{r}\text { Boehm titration }(\mathrm{m} . \mathrm{eq} / \mathrm{gm}) \\
\mathrm{NaOH}\end{array}$ & 1.040 & \\
\multicolumn{1}{c}{$\mathrm{Na}_{2} \mathrm{CO}_{3}$} & 1.40 & 1.560 \\
\hline $\mathrm{NaHCO}$ & 0.520 & 1.44 \\
\hline Iodine Number $\mathrm{mg} / \mathrm{g}$ & 2121.457 & 0.16 \\
\hline Surface Area & 57.13 & 2743.555 \\
\hline & & 92.12 \\
\hline
\end{tabular}


The yield and iodine number of CAC and CSC are85.2\% and $2121.457 \mathrm{mg} / \mathrm{g}$ and $91.6 \%$ and $2743.555 \mathrm{mg} / \mathrm{g}$ respectively. The higher the yield and iodine value, the higher will be the uptake ability of the composites. So CSC has more tendencies to uptake pollutants than CAC. CSC has the surface acidity of $3.25 \mathrm{mmoles} / \mathrm{gm}$ and $3.775 \mathrm{mmoles} / \mathrm{gm}$ respectively. Basicity of these composites is $4.00 \mathrm{mmoles} / \mathrm{gm}$ and $4.164 \mathrm{mmoles} / \mathrm{gm}$. Boehm titration method is employed for the determination of acidity and basicity. The basic and oxygenated acidic surface groups of the composites are quantifying by Boehm titrations. ${ }^{27}$ The surface area of the chitosan is $1.46 \mathrm{~m}^{2} / \mathrm{g}$. After modification with Alumina $\left(57.13 \mathrm{~m}^{2} / \mathrm{g}\right)$ and Silica $\left(92.12 \mathrm{~m}^{2} / \mathrm{g}\right)$ the surface area is increased. ${ }^{28}$ The Zpc of CAC and CSC are $6.5 \& 7.8$ respectively. Below this Zpc composite uptake the cationic dye due to its negative charge density and above this Zpc composite uptake the anionic dye due to its positive charge density.

\section{SEM Analysis}

The SEM images of Chitosan Alumina Composite (CAC) and Chitosan Silica Composite (CSC) are shown in Figure-1a and 1b. Figure-1a shows the surface of CAC has combined petal-like structures. The high surface area of Chitosan Alumina Composite is due to porous structure. The Figure-1b displays the SEM image of Chitosan Silica Composite; it shows its highly porous structure. ${ }^{29}$

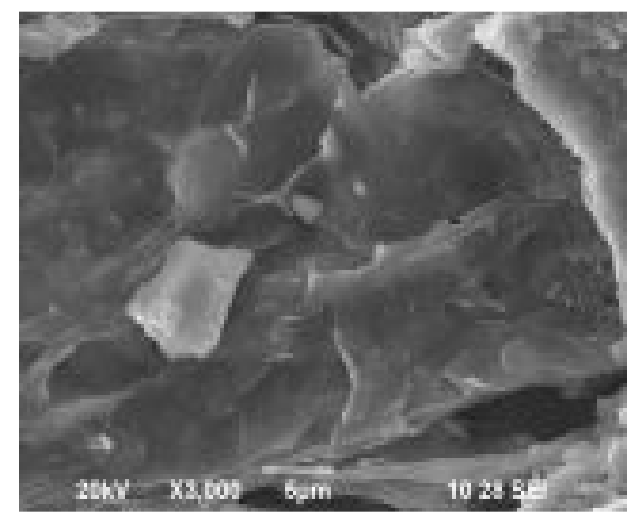

Fig.-1a: SEM image of CAC

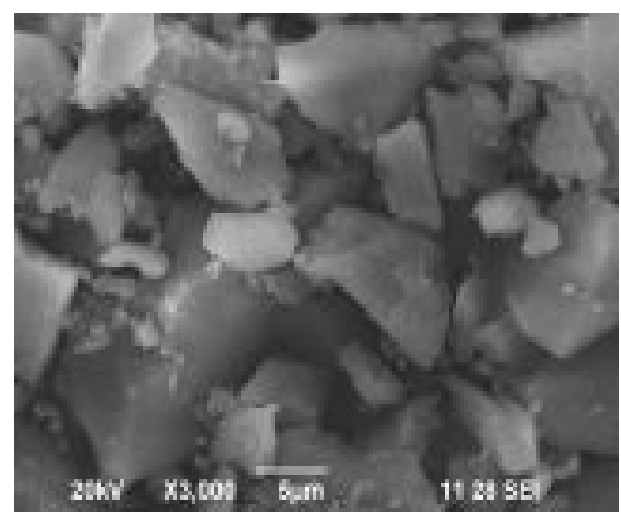

Fig.-1b: SEM image of CSC

\section{Energy-dispersive X-ray spectroscopy (EDX)}

The EDX spectra of CAC and CSC are given in the Figure-2a and $2 b$ which indicates the presence of respective ions in the composites. In Figure-2athe aluminum sorption has occurred on CAC is confirmed by the presence of aluminum. In Figure- $2 b$ the silica sorption appears on CSC is confirmed by the presence of silica in EDX results in. ${ }^{30}$

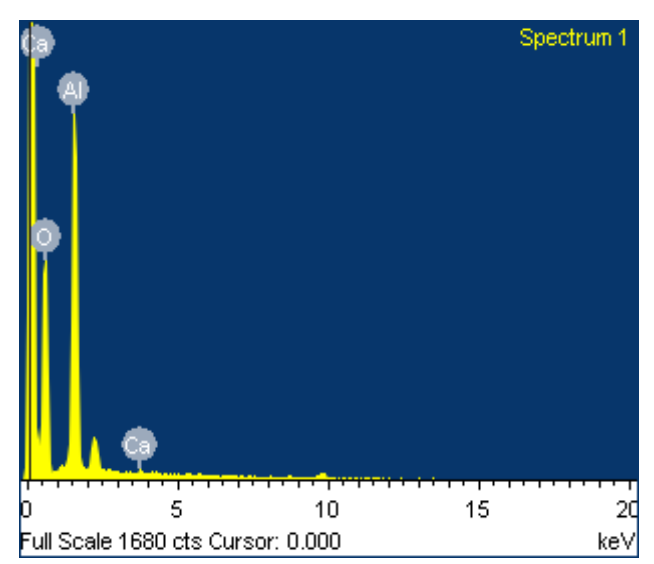

Fig.-2a:EDAX image of CAC

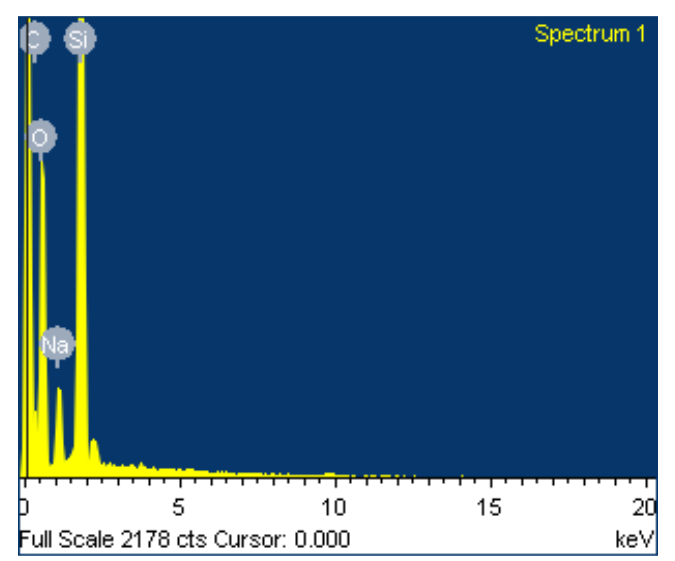

Fig.-2b:EDAX image of CSC 


\section{X-Ray refractory diffraction (XRD)}

The prepared composites CAC and CSC are characterized by X-ray refractory diffraction (XRD). From Fig-3a and $3 b$ there are no appreciable changes in the spectra. XRD measurement indicates that CAC and CSC are less amorphous and small crystalline in nature. It is proved by the $2 \theta$ values it lies between 20 $30^{\circ} .{ }^{30}$

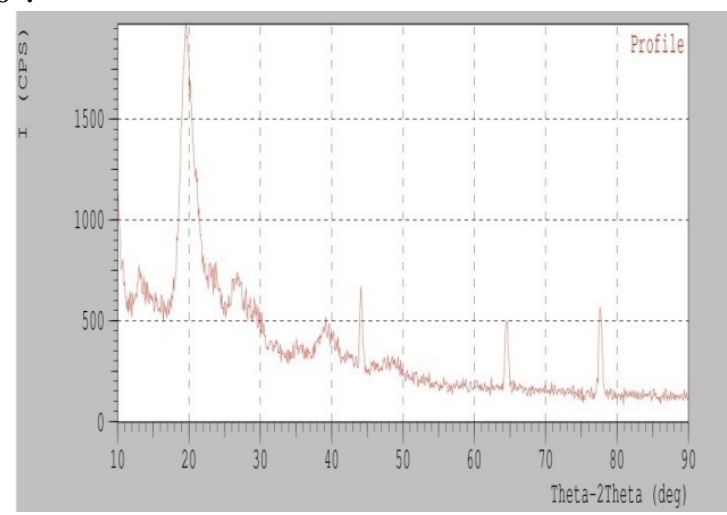

Fig.-3a:XRD image of CAC

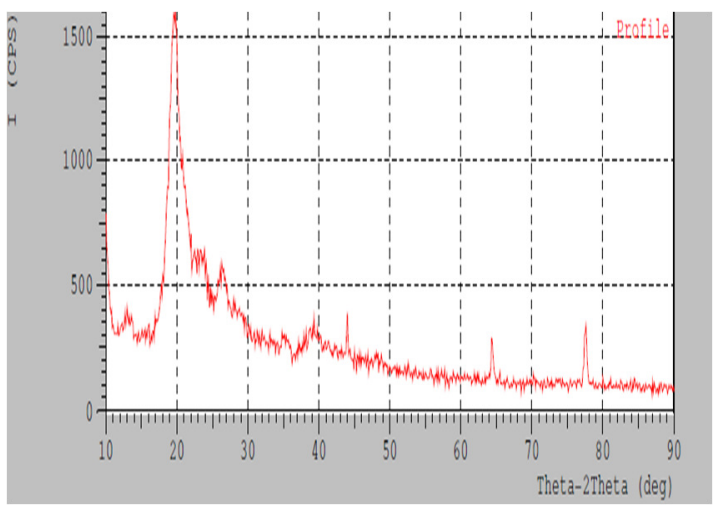

Fig.-3b: XRD image of CSC

\section{FTIR Analysis}

The FTIR spectrum of CAC shown in Fig-4a. The wide band at $3461.41 \mathrm{~cm}^{-1}$ shows the presence of OH and $-\mathrm{NH}$ stretching vibrations. The peak at $3189.43 \mathrm{~cm}^{-1}$ shows the presence of $-\mathrm{NH}$ stretching band ${ }^{31}$ and the peak around $1573.98 \mathrm{~cm}^{-1}$ shows the presence of $\mathrm{NH}$ bending in $-\mathrm{NH}_{2}$. The peak present at $1384.95 \mathrm{~cm}^{-1}$ indicates the presence of methyl group. The band at $1069.57 \mathrm{~cm}^{-1}$ shows the presence of $\mathrm{CO}$ stretching vibration in band $\mathrm{C}-\mathrm{OH} .{ }^{32}$ The band observed between $1000-500 \mathrm{~cm}^{-1}$ could be the characteristic vibrations of aluminium oxide. ${ }^{33,34}$ The peak around $544.91 \mathrm{~cm}^{-1}$ shows the presence of metal oxygen stretching.

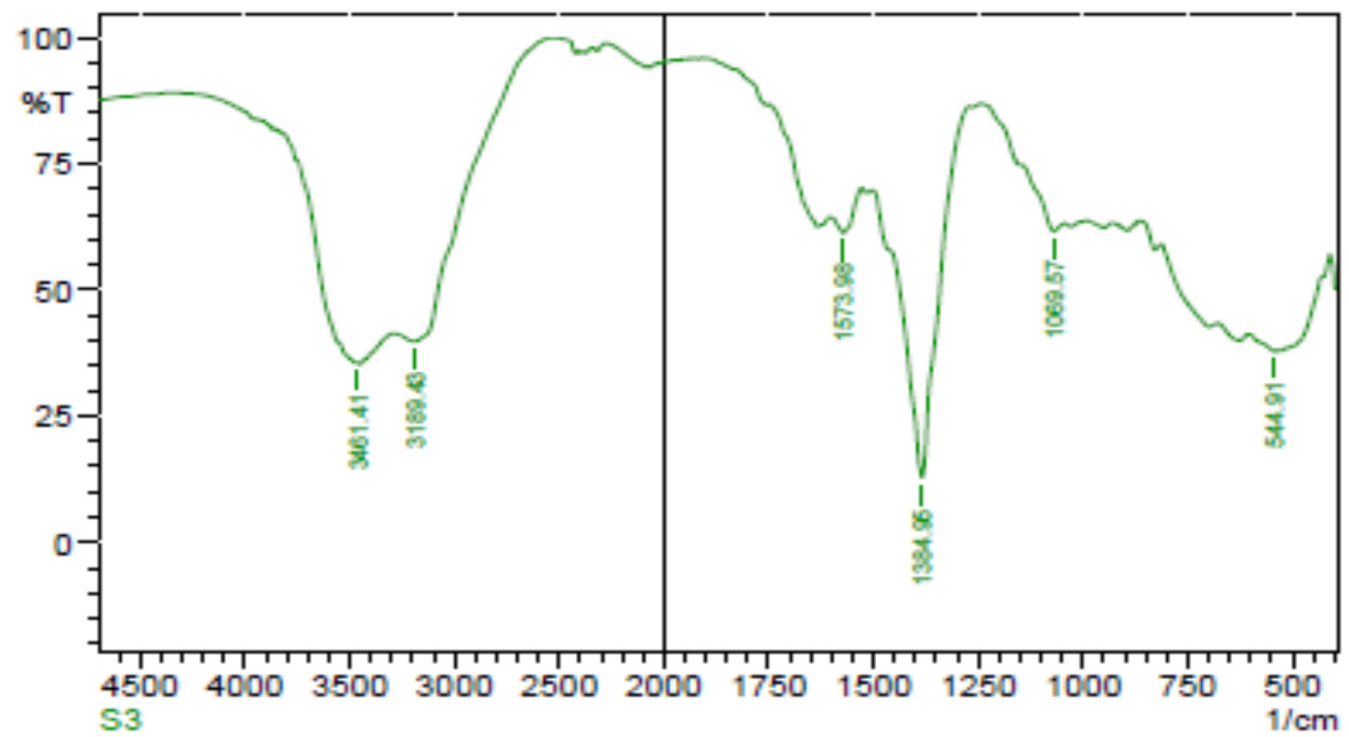

Fig.-4a: FTIR spectrum of CAC

The FTIR spectrum of CSC is shown in Figure-4b. The intense band at $3449.84 \mathrm{~cm}^{-1}$ shows the presence of $\mathrm{OH}$ adsorption. The peak about $1648.24 \mathrm{~cm}^{-1}$ indicates the presence of $\mathrm{C}=\mathrm{O}$ stretching and the peak around $1561.44 \mathrm{~cm}^{-1}$ shows the deformation vibration of $-\mathrm{NH}_{2}{ }^{35}$ The peak present at $1415.81 \mathrm{~cm}^{-1}$ indicates the presence of $\mathrm{C}-\mathrm{H}$ bending vibration. The peak at $1082.11 \mathrm{~cm}^{-1}$ shows the presence of Si-O stretching vibration. The peak around $463.90 \mathrm{~cm}^{-1}$ shows the presence of sulphur. ${ }^{36}$ 


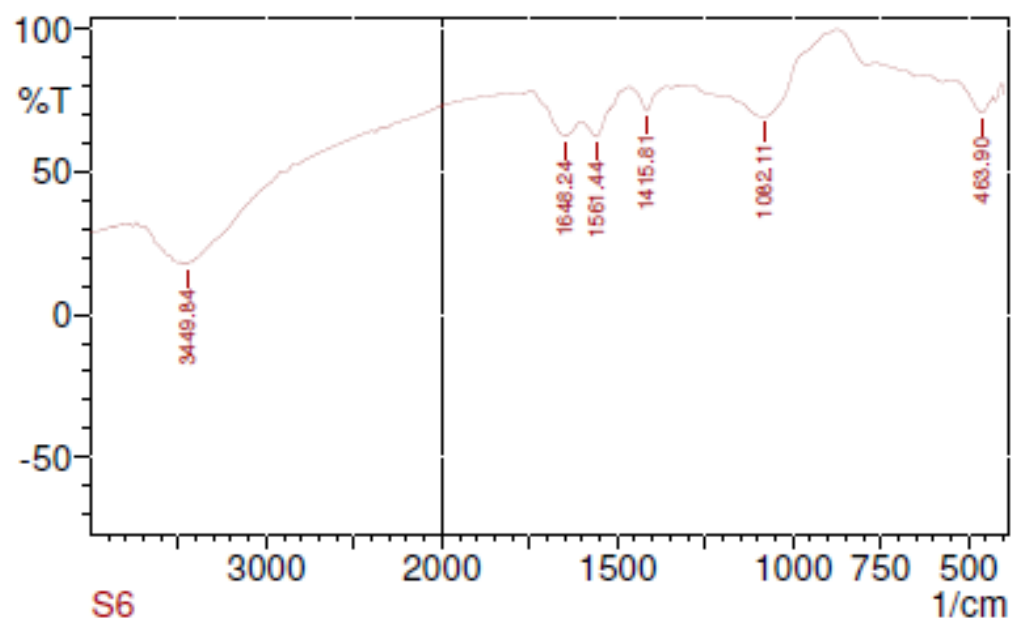

Fig.-4b: FTIR spectrum of CSC

\section{CONCLUSION}

This paper is aimed to optimize the preparation procedure of CAC and CSC composites based on chitosan. It is found that the preparation procedure affects the morphology of the composite beads formed at higher basicity of the solution have more irregular spherical shape. The results indicate that if the yield increases Iodine number is also get increases, similarly the moisture content of the CSC is less than CAC. So the prepared composites could be effectively used in the wastewater treatment.

\section{REFERENCES}

1. T. Santhi, S. Manonmani, T. Smitha and K. Mahalakshmi, Rasayan J.Chem., 2(4), 813(2009).

2. M. S. Chiou and H. Y. Li, Dyes, and Pigments, 60, 69(2004).

3. H. Wang MoJ, J. U. Jegal, J. Kim, Dyes and Pigments,72, 240(2007).

4. F. R. Rijsberman, Agric. Water Manage, 80,1(2006).

5. S. Al-Asheh, F. Banat, L. Abu-Aitah, Sep. Purif. Technol, 33(1-10), 1383(2003).

6. Masood Alam, Mohd. Aslam and Sumbul Rais, Rasayan J.Chem, 2(4), 791(2009).

7. G. Crini, Bioresour. Technol, 97, 1061(2006).

8. M. R. Fat'hi, H. Parham, N. Pourreza, H. Golmohammadi, Fresenius Environ Bull, 21, 1873(2012).

9. A. Basker, P. S. Syed Shabudeen, S. Daniel and P. Vignesh Kumar, Rasayan J.Chem, 7(1), 1(2014).

10. C. Namasivayam and N. Kanchana, Chemosphere, 25, 1691(1992).

11. J. Synowieckiand, N. A. Al-Khateeb, Cri.t Rev. Food Sci. Nutr, 43, 145(2003).

12. J. R. Evans, W. G. Davids, J. D. MacRae, A. Amirbahman, Water Res., 36, 3219(2002).

13. F. Wu, R. Tseng, R. Juang, J. Hazard. Mater, 73, 63(2000).

14. G.Yao Lu, X. Wu, T. Zhan, Microchem. J., 69, 81(2001).

15. E. Guibal, L. Dambies, C. Milot, J. Roussy, Polym. Int .,48, 671(1999).

16. W. S. W. Ngah, K. H. Liang, Ind. Eng. Chem. Res, 38, 1411(1999).

17. Z. Yang, L. Zhuang, G. Tan, J. Appl. Polym. Sci, 85, 530(2002).

18. E. Guibal, T. Vincent, R. N. Mendoza, J. Appl. Polym. Sci, 75, 119(2000).

19. Z. Yang and Y. Yuan, J. Appl. Polym. Sci, 82, 838(2001).

20. Jayshri A. Thote, Ravikrishna V. Chatti, Kartik S. Iyer, Vivek Kumar, Arti N. Valechha, Nitin K. Labhsetwar, Rajesh B. Biniwale, M. K. N. Yenkie, Sadhana S. Rayalu, J. Environ Sci., 24(11), 1979 (2012).

21. M. Y. Chang and R. S. Juang, J. Colloid. Interface Sci, 278, 18(2004).

22. M. Hasan, A. L. Ahmad, B. H. Hameed, Chem. Eng. J., 136, 164(2008).

23. A. Kumar, B. Prasad, I. M. Mishra, J. Hazard. Mater., 152(2), 589(2008).

24. O. S. Bello, M.A. Ahmad, T. T. Siang Trends Appl. Sci. Res., 6(8), 794(2011). 
RASĀYAN J. Chem.

Vol. 10 | No. 3 |759 - 765 | July - September | 2017

25. H .P. Boehm, E. Diehl, W. Heck, R. Sappok, Angew Chem. Int. Edit., 3, 669(1964).

26. S. R. Sugunadevi, M. Sathish Kumar, K .Shanthi, K. Kadirvelu, S. Pattabhi, J. Environ .Prot,22(5), 500(2002).

27. M. Makeswari and T. Santhi, Int. J. Mod. Eng. Res., 3(5), 3255(2013).

28. A. Muniyappan, Rajiv Gandhi, Natrayasamy Viswanathan, S. Meenakshi, Int. J. Biol. Macromol., 47, 146(2010).

29. Rathinam Karthik and Sankaran Meenakshi , J. Water Process Eng., 1, 37(2014).

30. M. Rajiv Gandhi and S. Meenakshi, Hazard .Mater, 203-204, 29(2012).

31. Suparna Saha, Priyabrata Sarkar, J. Hazard. Mater, 227-228, 68(2012).

32. V. M. Boddu, K. Abburi, J. L. Talbott, R. Smith, Haasch, Water Res, 42, 633(2008).

33. D. Das, J. Parida, Colloid Interface Sci., 261, 213(2003).

34. A. Legrouri, Badreddine, A. Barroug, D. Roy, J. P. Besse, J. Mater. Sci. Lett, 18, 1077(1999).

35. J. Yu, M. Tong, X. Sun, B. Li, Bioresour. Technol., 99, 2588(2008).

36. J. Lin, J. A. Siddiqui, R. M. Ottenbrite, Polym. Adv. Technol., 12, 285(2001).

[RJC-1752/2017] 